\title{
Design of Smart Vehicle to Detect Unauthorized Access and Theft Detection
}

\author{
K.Cornelius, M. Grace Prasana, J. Jaya Prakash, M. Sasi Kumar, K.T. Nivas Kumar
}

\begin{abstract}
Today within the current international situation safety and particularly security of car in common parking places has become a main concern. During this system easy and cheaper vehicle following is enforced with the assistance of world Positioning System (GPS), and international System for Mobile Communication (GSM) technologies. the most parts within the system area unit GPS module, GSM modem, IR sensor, RFID reader and microcontroller. the utilization of GPS system is to trace this location of the vehicle. As GPS system will solely receive the vehicle location data from the satellites, GSM system is additionally put in within the vehicle for causing data to vehicle's owner. Just in case of towing and break open of car this technique mechanically sends the SMS to have and a speed system in it.
\end{abstract}

\section{Keywords: RFID, IR Sensors, GPS and GSM, Ignition switch}

\section{INTRODUCTION}

The theft detection in cars have become a major issues so we have taken survey that almost $30 \%$ of the vehicle have been stolen every year. This is due to consciousness of the person who ones the vehicle so we have developed a theft detection system. When a vehicle is stolen we have two mode of operation auto and manual it has direct connection with vehicle unit to control speed limit and GPS and GSM are used to send the location to the vehicle owner when a vehicle is stolen. We use GPS to track the exact location of the vehicle.

We use GSM for sharing the message and control the speed limit of the vehicle. If the rider is getting over speed it will notify the rider to reduce the speed of the vehicle. If the vehicle is towed it will send a message.

\section{LITERATURE SURVEY}

M. Abinaya ${ }_{[1]}$ Currently nearly of the general public having associate own vehicle, stealing is going on on parking and typically driving in security places. The safe of vehicles is extraordinarily essential for public vehicles. Vehicle security and accident bar is more difficult. thus so as to bring an answer for this downside this method are often enforced. Vehicle security sweetening and accident

Revised Manuscript Received on 14 September, 2019.

K.Cornelius, Assistant Professor, Department of Computer Science \& Engineering, St. Peter's Institute of Higher Education and Research, Chennai, Tamilnadu, India. (Email: cornelius851@gmail.com)

M. Grace Prasana, Assistant Professor, Department of Computer Science \& Engineering, St. Peter's Institute of Higher Education and Research, Chennai, Tamilnadu, India. (Email: gr_prasana@yahoo.com)

J. Jaya Prakash, UG Student, Department of Computer Science \& Engineering, St. Peter's Institute of Higher Education and Research, Chennai, Tamilnadu, India. (Email: jayaprakashj15061999@gmail.com)

M. Sasi Kumar, UG Student, Department of Computer Science \& Engineering, St. Peter's Institute of Higher Education and Research, Chennai, Tamilnadu, India. (Email: sasi.kummar9@gmail.com)

K.T. Nivas Kumar, UG Student,Department of Computer Science \& Engineering, St. Peter's Institute of Higher Education and Research, Chennai, Tamilnadu, India. (Email: nivas.6268@gmail.com) bar system are often developed through the applying of ignition management (tracking and locking), fuel theft, accident detection and bar, driver fatigue, pollution management and speed limiting with economical vehicle management system. the requirement for this project is to supply security to the vehicles by engine lockup system that prevents the vehicle from unauthorised access. this system helps to search out out the precise location of the accident associated with the assistance of server an emergency vehicle are often sent to the precise location to cut back the human life loss. It conjointly detects the behaviour of the driving force through sensors whether or not he/she is drowsy or drunk, so incidence of accident are often prevented. The place of the vehicle known victimisation international Positioning system (GPS) and international system mobile communication (GSM).This is a lot of secured, reliable and low price.

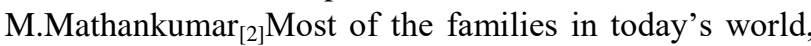
own a car. As the number of cars purchased will increase, the thieving rate conjointly increases. Thus, the demand for associate car guard system is augment. This technique makes use of a frequencies Identification (RFID) tag to spot the unauthorized access. The microcontroller uses a hidden camera to require an image of the person within the automobile and mechanism to manage the engine. The Global System for Mobile communication (GSM) is employed by the system to transmit interloper knowledge and also the captured image to the owners. the worldwide Positioning System (GPS) helps the owner to understand the situation of the automobile wherever it's lost. This system is constructed with ATmega16 controller that controls and coordinates all the processes. ancient anti-theft systems depend on varied sensors that don't offer responsibility. Thus, this technique can merge safeguard, following and remote control of automobile.

HemantKuruva $_{[3]}$ Most of the families in today's world, own a car. As the number of cars purchased will increase, the stealing rate conjointly increases. Thus, the demand for Associate in nursing motor vehicle guard system is augment. This method makes use of aoftenness Identification (RFID) tag to spot the unauthorized access. The microcontroller uses a hidden camera to require an image of the person within the automotive and mechanism to manage the engine. The Global System for Mobile communication (GSM) is employed by the system to transmit unwelcome person knowledge and therefore the captured image to the owners the worldwide Positioning System (GPS) helps the owner to understand the situation of the automotive wherever it's lost. 
This system is constructed with ATmega16 controller that controls and coordinates all the processes. ancient anti-theft systems depend on numerous sensors that don't give reliableness. Thus, this method can merge safeguard, chase and remote control of automotive.

RaunakAgrawal $_{[4]}$ The crime associated with vehicle felony has been an amazing rise with burglar's changing into smarter each day. This generates associate crucial want for a good vehicle felony identification system. During this paper, a compact, low cost and economical system is studied, designed and explored mistreatment Raspberry Pi because the core process unit of the entire system. Sensors information of Passive Infra-Red (PIR) motion sensing element, pressure sensing element, gas sensor, as well as world Positioning System (GPS), Pi camera, buzzer and a liquid show (LCD) show ar collected by embedded UNIX system. The device functions in 2 modes: User mode and felony mode. The contrivance has ability of detective work intrusion associated on detection can ring an alarm and send coordinates to the user's allotted E-mail. The device can send the latitude and longitudinal details to the user's e-mail at the side of the captured image mistreatment remote sensing whenever there's associate intrusion or if the device is displaced when an explicit threshold as within the case of bike felony whereby the whole vehicle is effortlessly displaced while not beginning the engine or deactivating physical locks. It is easy to find the vehicle and acquire correct position on Google Maps mistreatment this style. This paper explores the likelihood of a compact, versatile, viable, low cost and economical vehicle felony detection system.

Ms.M.Vinodhini ${ }_{[5]}$ In automobile field, the protection and thievery bar area unit one amongst the most areas in current state of affairs. The protection goals area unit achieved by the GSM, GPS technology. However with the rise of variety of vehicles, the protection of vehicles becomes additional complicated and insecure, thus there's additional demand of safety and security of the vehicle instead of solely observation its location. Currently the additional intelligent systems area unit deployed with increasing quality, which is able to conjointly offer some further advantages to the vehicle users. to satisfy these needs, the good system must be developed. During this paper, we tend to propose a sensible system which is able to be supported Microcontroller, GPS, GSM and RFID technology, for the observation, dominant and security of the vehicle. The place of the vehicle is known victimization international Positioning System (GPS) and international System for Mobile Communication (GSM). These systems perpetually watch the movement of auto and report the standing on demand. once the thievery is known, the accountable person send SMS to the microcontroller, then microcontroller issue the management signals to prevent the engine motor. To restart the vehicle motor, licensed person ought to send the parole to controller and open the door. This is often additional secured, reliable and low value. This good system can helps to the vehicle owner or/and operational manager of transport business to work their vehicles with most security and potency by gaining the important time insights from the remote vehicle.

\section{EXISTING SYSTEM}

At this time, the speed of crime is increasing apace as a result of it's a form of evident from the particular undeniable fact that thefts became a matter of routine. significantly these vehicles might incur Brobdingnagian losses on the a part of the quantity endowed on these vehicles.

\section{DISADVANTAGES OF EXISTING SYSTEM}

- A lot of stolen vehicles used to be identified and recovered in another jurisdiction different from where they were stolen either by police or civil society but due to lack of up-to-date information system

- It is less effective at times due to some challenges to tracking.

- $\quad$ Signal distortion and lack of power source.

\section{PROPOSED SYSTEM}

To overcome this downside, there area unit varied technologies area unit obtainable within the market like GPS, GSM and GPRS systems. within the gift days, most of the vehicles area unit designed with GSM based mostly vehicle thievery management systems, that provides the protection from thefts although they're set within the lot.The projected methodology presents the researchers framework for achieving a lot of value effective vehicle thievery alert and identification system. The framework proposes the use of the GPS, GSM and the internet technologies.

\section{Hardware requirement:}

LCD, GPS, GSM, Microcontroller,RFID, Ignition Switch key, Arduino Nano.

\section{Software Requirement :}

Embedded C

Architecture of proposed system:

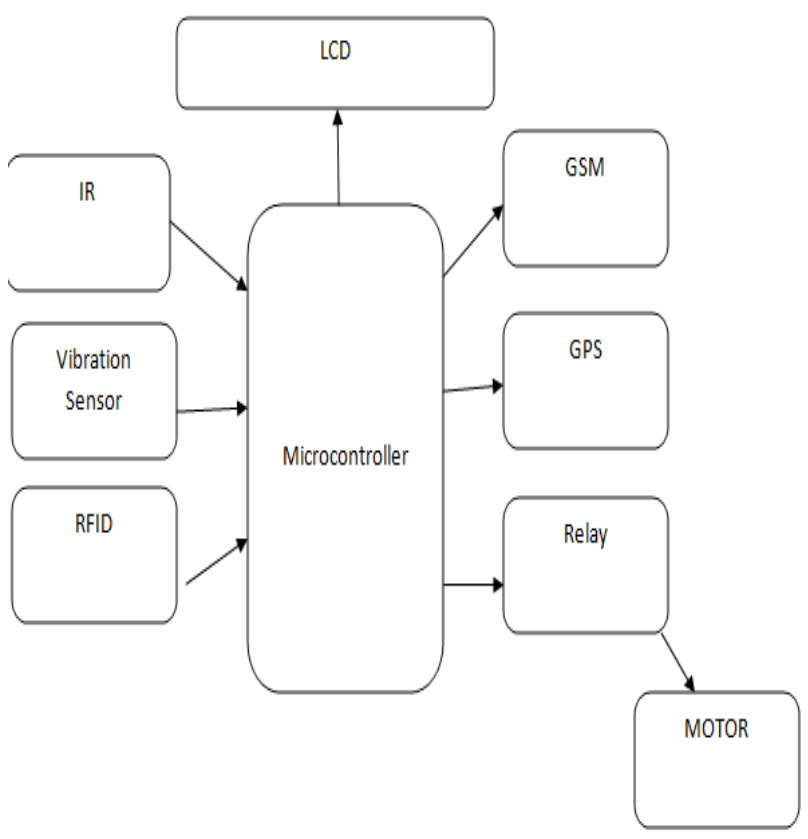

Fig.1.Working Model

Published By: Blue Eyes Intelligence Engineering 


\section{LCD Display:}

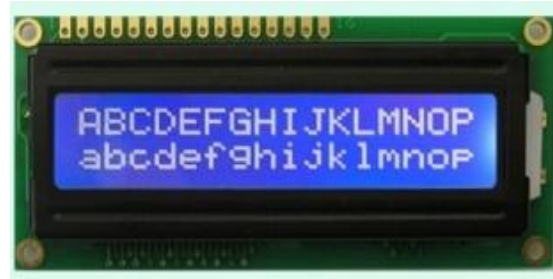

Fig.2.LCD Display

LCD modules area unit vey normally utilized in most embedded comes, the explanation being its low cost value, accessibility and applied

scientist friendly.Most people would have stumble calculators. The looks and therefore the pinouts have already been visualised on top of currently allow us to get a small amount technical.There areaunit heaps of mixtures offered li $\mathrm{ke}, 8 \times 1,8 \times 2,10 \times 2,16 \times 1$, etc. however the foremost used one is that the $16 \times 2$ liquid crystal display. So, it'll have $(16 \times 2=32)$ thirty two characters in total and every character are made from $5 \times 8$ picture element Dots. one character with all its Pixels is shown within the below image. 16x2 liquid crystal display picture element.Now, we all know that every character has $(5 \times 8=40)$ forty Pixels and for thirty two Characters we are going to have $(32 \times 40) 1280$ Pixels.

RFID:

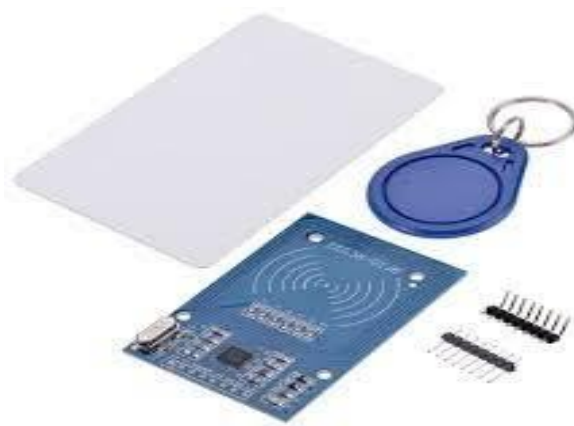

Fig.3.RFID

RFID is associate degree descriptor for "radio-frequency identification" and refers to a technology whereby digital information encoded in RFID tags or good labels (defined below) square measure captured by a reader via radio waves. RFID is comparable to barcoding in this information from a tag or label square measure captured by a tool that stores the information in an exceedingly information. RFID, however, has many benefits over systems that use barcode plus following package. the foremost notable is that RFID tag information are often scan outside the line-of-sight, whereas barcodes should be aligned with associate degree optical scanner. If you're considering implementing associate degree RFID answer, take successive step and speak to the RFID consultants at $A B \& R \circledast$ (American Barcode and RFID). RFID belongs to a bunch of technologies said as Automatic Identification and information Capture (AIDC). AIDC ways mechanically establish objects, collect information regarding them, and enter those information directly into pc systems with very little or no human intervention. RFID ways utilize radio upon these displays in our day to day life, either at PCO's or

waves to accomplish this. At a straightforward level, RFID systems comprises 3 components: associate degree RFID tag or good label, associate degree RFID reader, associate degreed an antenna. RFID tags contain associate degree computer circuit associate degreed an antenna, that square measure wont to transmit information to the RFID reader (also referred to as associate degree interrogator). The reader then converts the radio waves to a additional usable style of information. data collected from the tags is then transferred through a communications interface to a number computing system, wherever the information are often hold on in an exceedingly information and analyzed at a later time.

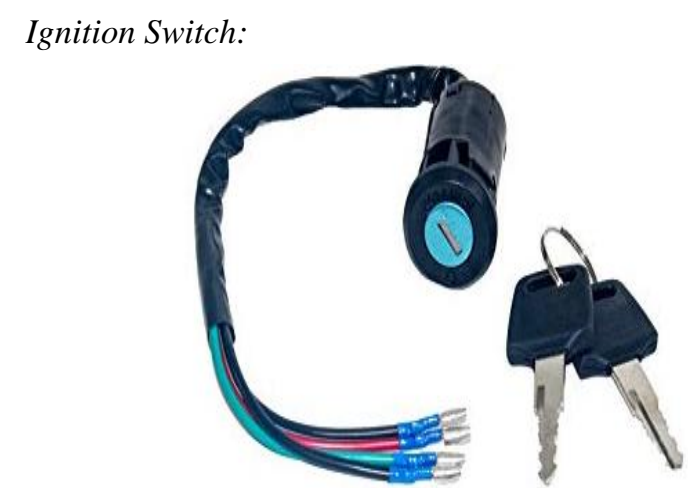

Fig.4.Ignition Switch

Ignition switches were key switches that needs the right key to be inserted so as for the switch functions to be unbolted. These mechanical switches stay present in trendy vehicles, additional combined with associate degree immobiliser to solely activate the switch functions once a electrical device signal within the secret's detected. However, several new vehicles are equipped with questionable "keyless" systems, that replace the key switch with a button. The ignition protection system could also be typically bypassed by disconnecting the wiring to the switch and manipulating it directly; this can be referred to as hotwiring.

GSM:

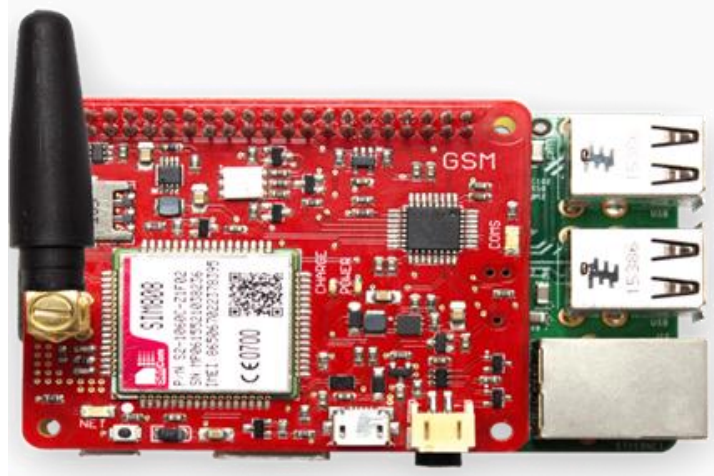

Fig.5.GSM Module

GSM stands for international System for Mobile communication. Today, GSM is employed by over 800 million finish users unfold across a hundred ninety countries

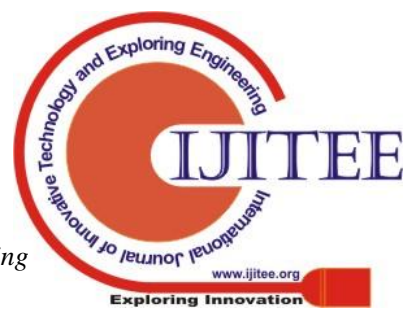


that represents around seventy \% of today's digital wireless market. So, let's see however it works. In GSM, geographical region is split into polygon cells whose facet depends upon power of transmitter and cargo on transmitter (number of finish user). At the middle of cell, there's a base station consisting of a transceiver (combination of transmitter ANd receiver) and an antenna. GSM may be a mobile communication modem; it's stands for international system for mobile communication (GSM). the thought of GSM was developed at Bell Laboratories in 1970. it's wide used mobile communication system within the world. GSM is AN open and digital cellular technology used for transmission mobile voice and knowledge services operates at the $850 \mathrm{MHz}, 900 \mathrm{MHz}, 1800 \mathrm{MHz}$ and $1900 \mathrm{MHz}$ frequency bands. GSM system was developed as a digital system victimization time division multiple access (TDMA) technique for communication purpose. A GSM digitizes and reduces the information, then sends it down through a channel with 2 totally different streams of consumer knowledge, every in its own specific slot. The digital system has a capability to hold sixty four kbps to one hundred twenty Mbps of information rates. GMS Modem GSM Modem There area unit numerous cell sizes during a GSM system like macro, micro, pico and umbrella cells.every cell varies as per the implementation domain. There area unit 5 totally different cell sizes during a GSM network macro, micro, pico and umbrella cells. The coverage space of every cell varies per the implementation atmosphere.

GPS:

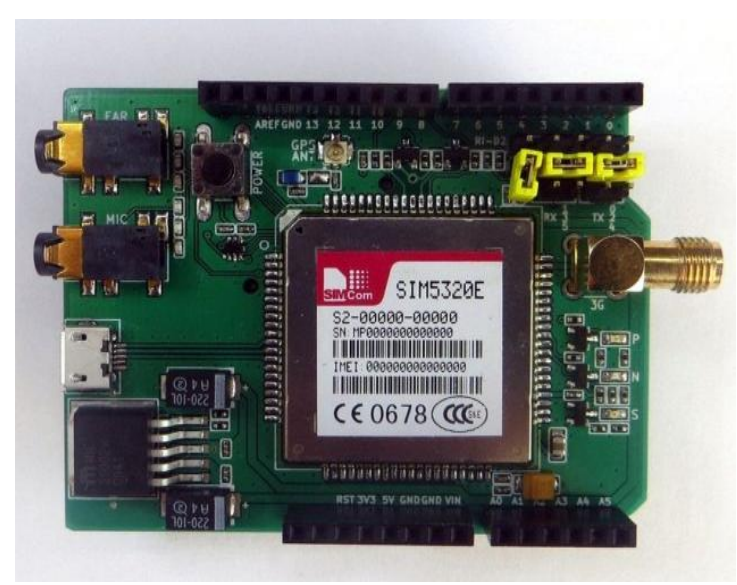

Fig.6.GPS Module

GPS is commonly employed by civilians as a navigation system. On the bottom, any GPS receiver contains a laptop that "triangulates" its own position by obtaining bearings from a minimum of 3 satellites. The result's provided within the style of a geographic position - meridian and latitude to, for many receivers, at intervals associate degree accuracy of ten to one hundred meters. package applications will then use those coordinates to supply driving or walking directions. Getting a lock on by the GPS receivers on the bottom typically takes it slow particularly wherever the receiver is in a very moving vehicle or in dense urban areas. The initial time required for a GPS lock is sometimes smitten by however the GPS receiver starts. There ar 3 kinds of begin - hot, heat and cold. The hot begin is once the GPS device remembers its last calculated position and therefore the satellites seeable, the almanac used (information concerning all the satellites within the constellation), the UT1 Time and makes a shot to lock onto identical satellites and calculate a replacement position primarily based upon the previous data. this can be the fastest GPS lock however it solely works if you're typically within the same location as you were once the GPS was last turned off. The warm begin is once the GPS device remembers its last calculated position, almanac used, and UT1 Time, however not that satellites were seeable. It then performs a reset and makes an attempt to get the satellite signals and calculates a replacement position. The receiver contains a general plan of that satellites to appear for as a result of it is aware of its last position and therefore the almanac knowledge helps determine that satellites ar visible within the sky. This takes longer than a hot begin however not as long as a chilly begin. And finally - the cold begin is once the GPS device dumps all the knowledge, makes an attempt to find satellites and so calculates a GPS lock. This takes the longest as a result of there's no known data. The GPS receiver must arrange to lock onto a satellite signal from any out there satellites, essentially like polling, that takes tons longer than knowing that satellites to appear for. This GPS lock takes the longest. In a shot to boost lock times, wireless telephone makers and operators have introduced the assisted GPS technology, that downloads this annual for a couple of days ahead via the wireless networks and helps triangulate the overall user's position with the cell towers therefore permitting the GPS receiver to urge a quicker lock at the expense of many (kilo)bytes

\section{Relay:}

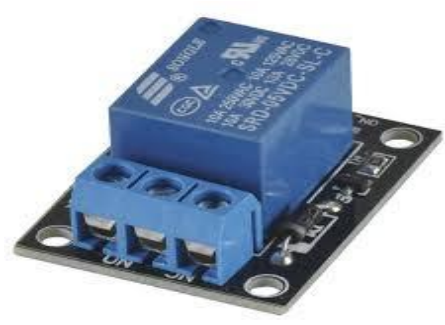

Fig.7.Relay

A relay is AN electrically operated switch. It consists of a collection of input terminals for one or multiple management signals, and a collection of operative contact terminals. The switch might have any range of contacts in multiple contact forms, like create contacts, break contacts, or mixtures there from. Relays area unit used wherever it's necessary to manage a circuit by AN freelance low-power signal, or wherever many circuits should be controlled by one signal. Relays were initial utilized in long-distance telegraph circuits as signal repeaters: they refresh the signal returning in from one circuit by transmittal it on another circuit. Relays were used extensively in phone exchanges and early computers to perform logical operations. 


\section{WORKING METHODOLOGY\& RESULTS}

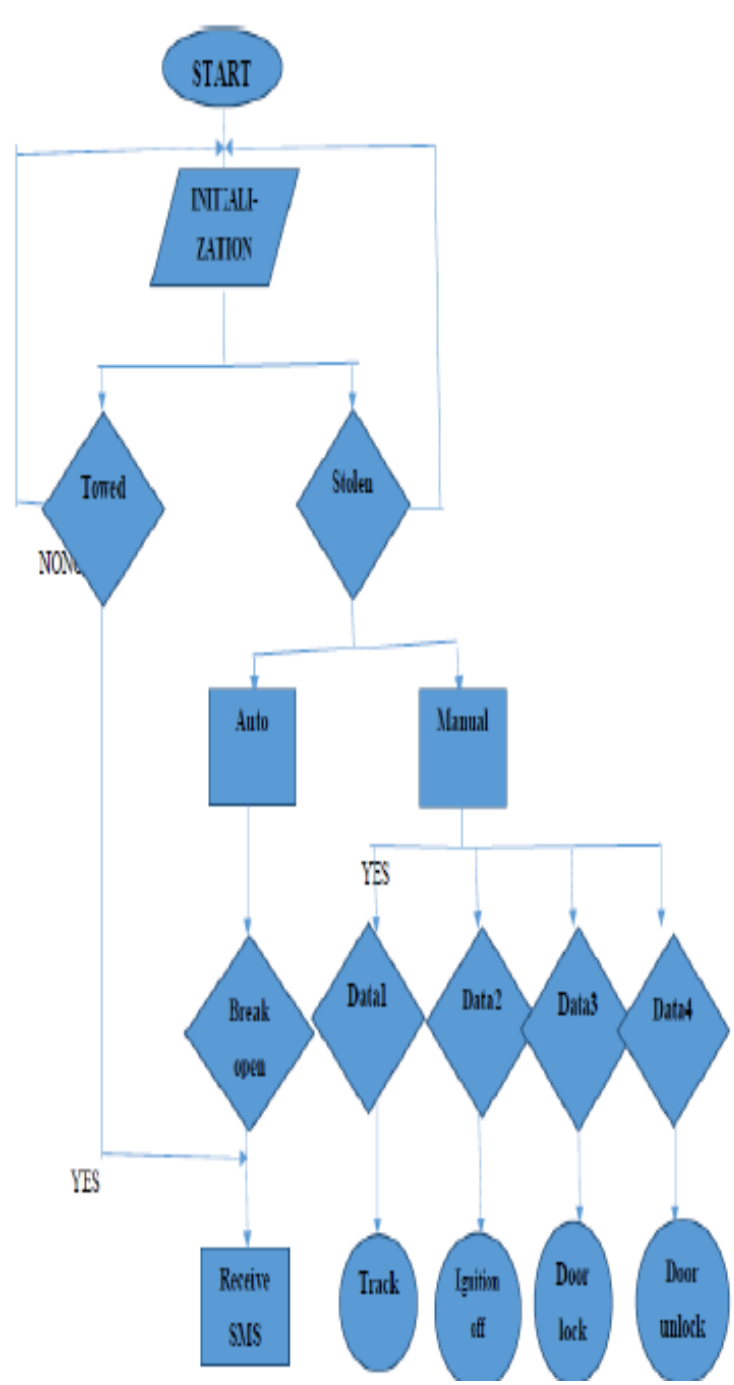

Fig.8.Working Methodology

\section{CONCLUSION}

We have developed a vehicles theft system, accidentdetection system with the speed system which ensures the safety of the rider. The vehicle's theft will give the location to the owner if the vehicle isstolen. The accident detection system is used to give the location to the person on their emergency list. The future enhancement of this project can be tracking the vehicles when the rider is alcoholic and halting it.

\section{REFERENCE}

1. M.Mathankumar1,SuryaprakashShanmuga sundaram2,Dr.P.Thirumoorthi3,U.Rajkanna4

Development of Smart Car Security System Using Multi Sensors. International Journal of Pure and Applied Mathematics Volume 117 No. 222017.

2. Raunak Agrawal1, Rahul Dugar2, Saurabh Surana3, Sunil Mp4, Hamsa S5 Design and Implementation of Smart Vehicle Theft Detection Using Raspberry Pi and Iot for Real Time Applications International Journal for Research in Applied Science \& Engineering Technology (IJRASET) Volume 6 Issue VI, June 2018.

3. 1Hemant Kuruva, 2Girish Shiva PrasannaRaju S. IoTbased anti-theft and remote controlling system for automobiles International Journal of Science,
Engineering and Technology Research (IJSETR) Volume 5, Issue 12, December 2016.

4. P. Senthil Raja, Dr.B.G.Geetha, Detection of Fuel Theft in heavy Vehicle. International Journal of Advanced Engineering Technology Vol. VII/Issue II/AprilJune, 2016.

5. Pranesh, S.I., \&Saravana, K. P. (2014). A Massive Vehicle Theft Control System using Embedded and Mobile Technologies. International Journal of Advanced Research (IJAR), 2 (4), 53-59.

6. Powale, P. K., \&Zade, G.N. (2014).Real Time Car Antitheft System with Accident Detection using AVR Microcontroller: A Review. International Journal of Advance Research in Computer Science and Management Studies (IJARCSMS), 2(1), 509-512.

7. Ramani, R., Valarmathy, S., Sutanthira, V. N., Selvaraju, S., Thiruppati, M., \&Thangam, R. (2013). Vehicle Tracking and Locking System based on GSM and GPS. International Journal for Intelligent Systems and Application(IJISA), 9, 86-93. DOI: 10.5815/ijisa.2013.09.10.

8. Shaikh, J.A. I., \&Subhangi, A. M. (2014).Advanced Authentication and Security System for Call Centre Journal of Advanced Research in Electrical, Electronics and Instrumentation Engineering (IJAREEIE), 3 (7), 10533 - 10536

9. Sriram, A. \&Ramya, P. (2013).Automatic Accident Notification System using GPS and GSM with 3G Technology for Vision Monitoring. International Journal of Emerging Trends in Electricals and Electronics (IJETEE),1(2), 11-13.

10. Yuvraj, K., Suraj, G., Shravan, G., \&Ajinkya, K. (2014) Multi-Tracking System for Vehicle using GPS and GSM. International Journal of Research in Engineering and Technology (IJRET), 3 (03), $127-130$.

11. Ali, A. \& Suleiman, A. (2015). A Security-Trust based Model for Identity Management Systems Adoption. Conference Proceedings Published by Institute of Information System and Research Center ( IISRC ) for 4th ICHCEIMS 2015 \& 4th ICCSISCT 2015 - Sydney, Australia. 19(2), 51-61.

12. S.Ancy, K.Cornelius, IOT based Smart Android Notification System, International Journal of Management, Technology And Engineering, Volume IX, Issue III, March/2019.

13. Akshatha, Anitha, Anusha, Prema, RumanaAnjum, Smart Helmet for Safety and Accident Detection using IOT, International Research Journal of Engineering and Technology (IRJET) Volume: 06 Issue: 03 | Mar 2019.

14. K. Vidhya, M. Kasiselvanathan, Smart Helmet and Bike System, International Journal of Recent Technology and Engineering (IJRTE), Volume-7 Issue-4S2, December2.

15. Mrs.N.S.Patil, Smart Helmet: An Application OfIot, International Journal of Advance Engineering and Research Development Volume 5, Issue 04, April -2018. 